\title{
Assessing the Mediating Role of Perceived Behavioural Control and Subjective Norm in the Relationship Between Perceived Food Quality and Students' Attitude Towards Food Waste
}

\author{
Louise Ellen Fabgemi Olu ${ }^{1}$ \\ Doreen $\mathrm{Adi}^{2}$ \\ Charlotte Caitoe ${ }^{3}$ \\ Yarhands Dissou Arthur ${ }^{4}$ \\ Akenten Appiah-Menka University of Skills Training and Entrepreneurial Development, Ghana ${ }^{1,2,4}$ \\ Barekese Senior High School, Ghana ${ }^{3}$
}

\begin{abstract}
This study assessed the effect of perceived food quality on SHS students' attitude towards food waste in Ghana. Further, the study looked at the mediating role of perceived behavioural control and subjective norm in this relationship. The study sampled 301 students from some selected second cycle institution in the Kumasi metropolis. Reliability test, convergence validity, and discriminant validity were assessed by running confirmatory factor analysis in Amos (v.23). The coefficients of the hypothesized paths were ascertained by running structural equation modelling (SEM). The study concludes that, perceived food quality, perceived behavioural control, and subjective norm, all had a direct positive effect on students' attitude towards food waste. Perceived food quality was also found to have had a direct positive effect on perceived behavioural control and subjective norm. Finally, perceived behavioural control and subjective norm were found to partially mediate the relationship between perceived food quality and students' attitude towards food waste.
\end{abstract}

Keywords: Perceived Behavioural Control; Subjective Norm; Perceived Food Quality; Attitude; Food Waste; Students.

Corresponding author: Charlotte Caitoe; E-mail: charttycaitoe@gmail.com DOI: https://doi.org/10.37227/ITHJ-2021-08-1108

\section{Introduction}

Food waste phenomenon is increasingly becoming a prime focus not only in research but also in the media, business and politics. The estimated food waste globally is about 1.3 hectic tons per year (FAO, 2014). About 30 to $50 \%$ of food that is produced go to waste and this clearly shows that rare commodity is allocated ineffectively (Wang et al., 2018). Starovoytova and Namango (2018) suggest high share of food waste (37\%) occurs in Kenya Universities which is attributed to the fact that meals are highly available and students buy the meals at cheaper prices. Their study reports that students take too much portion than they can eat 'and discard greater part of the food served to them at the canteen. They further stated that the situation calls for a change in behaviour. Quested et al. (2013) 
asserted that food waste is generally the result of multiple behaviours that are performed over time and this complexity of behaviours at different time points increases the likelihood of waste. According to a report by the Chefs for Change Ghana Foundation (CFCG), more than 45 percent of food in Ghana is not consumed and therefore goes to waste (Ghana Web, 2017).

Food waste refers to food for human consumption being discarded, whether or not after it is kept beyond its expiry date or left to spoil (FAO, 2013). Food losses and food waste have been recognized widely as the main barrier to attaining global sustainability (Wang et al., 2018). Growing attention to food loss and waste is considered in the Sustainable Development Goals (SDGs). SDG Target 12.3 calls for halving per capita global food waste at the retail and consumer levels and reducing food loss along production and supply chains (including post-harvest losses) by 2030. Large quantities of food waste have crucial sustainability impacts because it depletes resources and also results to high levels of greenhouse emission (Graham-Rowe, Jessop \& Sparks, 2019). Beside the environmental impact of food waste, Marx (2015) reported that it is ethically unjustifiable to waste food in a world where one out of nine people do not have sufficient access to nutrition. In this regard, it is important that the levels of food wasted be reduced.

Beretta et al. (2013) and Parfit et al. (2010) believe that consumers are the sole topmost generators of food waste. Accordingly, Quested et al. (2013) revealed that consumers waste about $330 \mathrm{~kg}$ of food per year per household in UK. Farr-Wharton, Foth and Choi (2014), however asserted that $65 \%$ of food waste generated could be averted by more sustainable behaviour, therefore, consumer behaviour ought to be changed urgently. It is of more significance that consumer behaviour changes not only in the private contexts such as home but also in the public contexts such as restaurants and in school service food unit. The president of the 4th Republic, Nana Addo Dankwa Akuffo Addo's governance brought up the Free Senior High School policy and it is seen by numerous people as a step in the right direction. Currently, the policy on the Free Senior High School education provides free education for students which includes free meals for boarding students. The policy of Free Senior High School aims at increasing enrolment, improving quality through academic performance and most importantly reducing the burden on parents from paying their wards school fees.

While food accessibility for the hungry and needy remains an issue, some amount of food served in some second cycle schools is a plate leftover and wasted. With the introduction of Free Senior High School Policy by the President Nana Addo Dankwa Akuffo Addo's Government (4th Republic of Ghana), it is anticipated that students' enrolment at school will keep increasing year by year, and for the purpose of the students to be well fed and adequately nourished, it is imperative to evaluate the factors associated with the food wastage behaviour of students in high schools. Owing to the ever-growing population in the free Senior High School, more food would have to be supplied in greater quantities and if food served is a plate leftover, it contributes to food wastage. Whereas a thriving attentiveness has been given to the evaluation and alleviation of post-harvest losses in developing and emerging countries (Affognon et al., 2015; African Post Harvest Losses Information System, 2011), data on student's food waste in the dining hall of second cycle schools in Ghana is largely missing. As Ghana gradually finds its feet in urbanization and the Free Senior High School Policy gradually becomes a pivot in the second cycle schools, and the supply of food by the government becomes more prominent, students' food wasting behaviour should be an issue of concern and therefore, more research and first hand data on their food waste should be of importance. When it comes to 
food waste as a phenomenon in second cycle schools in Ghana, there seems to be a gap in the literature to that effect and so our study seeks to address that gap.

\section{Objectives}

Our objectives may lay out an innovative strategy in the approach of students' attitude towards food waste with regards to how they perceive the quality of the food served to them. Our survey was conducted by selecting students from the second cycle schools in the Kumasi Metropolis with the following outlined objectives to be achieved:

- To determine the effect of perceived food quality on students' attitude towards food wastage.

- Examine the mediatory role of perceived behavioural control and subjective norm in students' attitude towards food wastage.

$\checkmark$ Determine the effect of food quality on perceived behavioural control and subjective norm.

\section{Literature Review \\ Relationship between Perceived Behavioural Control and Attitude towards Food Waste}

The increasing occurrence of food waste across the world over has caused many environmentalists to suggest diverse ways to curb its occurrence (Priefer, Jorissen, \& Braautigam, 2016). Over time, much of these discussions have placed more emphasis on how the antecedents of planned behavioural theory; perceived behaviour control, subjective norms and attitude accounts for food waste. A study by Hasana. Harun and Hock (2015) looked out for the main factors that affect a person attitude towards plastic waste consumption. Results from the study showed that perceived behavioural control had a significant influence on the students' attitude towards plastic waste consumption. Again, it was also established that there is statistically significant difference between genders when it came to their attitude towards plastic waste consumption.

In Denmark, Stancu, Haugaard and Làhteenmàki (2016) explored the connection between psycho-social factors, food-related routines, household perceived capabilities and socio-demographic characteristics on self-reported food waste. Specifically, the study sought to assess the respondents' attitude towards food waste, planning, shopping and reuse of remains, perceived capability to deal with household food-related activities, injunctive and moral norms, attitudes towards food waste, and perceived behavioural control. Results from the study showed that perceived behavioural control and habits associated with shopping and reuse of leftovers were the main predictors of the respondents' attitude towards food waste. Results from the study of Hasana et al. (2015) and Stancu et al. (2016) happen to be consistent with the conclusions of (Russell, Young Unsworth, \& Robinson, 2017) as their results revealed a significant relationship between perceived behavioural control $(\beta=0.37, p<.001)$ and respondents' attitude towards food waste. Specifically, their study sought to investigate consumer food waste behaviour using a comprehensive model integrating the theory of planned behaviour (TPB), the theory of interpersonal behaviour, and the comprehensive model of environmental behaviour. Guided by a temporally lagged design, a total of one hundred and seventy-two participants responded to four questionnaires within a 14 months period. The questionnaire assessed emotions in reference to food waste, routines, theory of planned behaviour antecedents, intention to lessen food waste, and self-reported food waste attitude. 
Again, a study done by Tsai, Chen and Yang (2020) in China investigated the factors that account for food waste among early adulthood consumers. Per the study's structural equation modelling (SEM), results from the study showed that perceived behaviour control had the most significant influence on the consumers attitude towards food waste. Results from the study of Stefan, van Herpen, Tudoran, and Lahteenmaki (2013) came by the same conclusion as their results identified perceived behavioural control as one of the key determinants of actual consumers waste in Romania. Also, in seeking to identify the main psychological factors that determine consumers food waste attitude, Soorani and Ahmadvand (2019) study results identified perceived behaviour control as the most significant predictor of the respondent's food waste attitude. In their study perceived behavioural control recorded the highest beta-coefficient value among all the other psychological factors used in their study.

\section{Relationship between Subjective Norm and Attitude towards Food Waste}

According to the theory of planned behaviour, subjective norms come from the social forces from people who occupy high offices or hold higher authority in society or organization (Ajzen, 2001). Often, the perception these individuals or persons with such high social status show towards a certain condition in this case food waste tend to have a significant influence on a person's attitude towards food waste. In the study of van der Werf and Seabrook (2019) subjective norm and personal norms all had a significant influence on the respondents' attitude towards food waste. For instance, subjective norm and personal norm both reduced a person tendency to engage in food waste. Similarly, in the studies of Quested, Marsh, Stunell and Parry (2013) and Stefan et al. (2013), subjective norm reported no significant influence on consumers attitude towards food waste.

Theoretically, some authors have linked the emerging insignificant relationship between subjective norm and consumer food waste behaviour to this reasonings. For instance, from the arguments of Quested, Parry, Easteal and Swannell (2011), since food waste behaviour are often times very difficult to be easily seen by other people particularly, neighbours or friends than probably pro-environmental behaviour (e.g., reusing or transport behaviours), the social normative movers of food waste behaviour are most likely to have less effect in shaping a person food waste behaviour. Graham-Rowe, Jessop and Sparks (2014) shared similar view by arguing that food waste is behaviour that is often solely visible to the creator, hence, the relevance of such person influence on another will often times be very difficult to result into any meaningful effect.

\section{Relationship between Perceived Food Quality and Attitude towards Food Waste}

One of the key factors that seems to trigger high volumes of food waste within households' level and the hospitality industry in general is the individual perception about food quality. A person's positive or negative experience with reference to a particular food will shape their perception on the wholesomeness of the food. According to Parasuraman, Zeithaml and Malhotra (2005), perceived quality depicts a consumer personal assessment about a product or service overall quality or dominance. However, what has to be noted is that a consumer perceived quality comes in a varied assessment criterion such as its physical properties, chemical structure, sensory qualities, microbiological and toxicological pollutants, shelf-life, packaging, and labelling (Molnar, 1995). Mijares, Alcivar and Palacios (2020) examined the relationship between food quality and food waste. This study used a survey design where adults who live in South Florida for 18 years or more are the primary provider of food for their households were recruited. With the factors that 
influence the respondents food waste, $90 \%$ threw their foods away or wasted them because they went bad with $80 \%$ throwing it away because it got past their manufacturing date.

Consistent result is produced in the study of Conrad et al. (2018) as their results reported a significant relationship between perceived food quality and food waste. Their study investigated the association between food waste, diet quality, nutrient waste, and multiple measures of sustainability. Accordingly, Conrad et al. (2018) recommended that improving consumers knowledge on how to adequately prepare and keep perishable foods such as fruits and vegetables will be very important in improving perception on food quality. A study done by Schiavone, Pistone, Finale, Guala and Attena (2020) assessed how patients' expectation on food quality provided to them at the hospital contributed to the amount of food wasted by the patients at the hospital. Apparently, results from the study suggest that the patients in the northern hospital were more enthused about the quality of food served them (i.e. $54.2 \%$ vs $36.0 \%)$ and entire food service $(54.5 \%$ vs $38.2 \%$ ) than patients from the southern hospital. Again, patients from the northern hospital had more positive expectations about the quality of food served (i.e. $69.5 \%$ vs $31.6 \%$ ) than patients from the southern hospital. Moreover, when it came to the impact the patients expectation about the quality of food served had on their food waste attitude, it was realized that patients from the southern hospital who had low expectation about the quality of food provided them threw a significant part of their food away (i.e. $41.7 \%$ of their food were discarded) than patients from the northern hospital who had positive expectation about the quality of food provided (i.e. only $15.3 \%$ of their food were discarded). Schiavone et al. (2020) concluded that consumer expectation about the quality of food provided to him or her tend to have a significant effect on the amount of food wasted by them.

\section{Mediating Effect of Perceived Behavioural Control and Subjective Norm in the Relationship between Perceived Food Quality and Attitude towards Food Waste}

As rightly argued by Mondéjar-Jiménez, Ferrari, Secondi and Principato (2016) the differences in individual food waste behaviour could be explained by other cofounding factors. For instance, whereas personal demographic profile inclusion in the theory of planned behaviour has improved its predictability of individual food waste behaviour, other situational factors such as emotions and awareness have equally enhanced the predictability of theory of planned behaviour. For instance, Scholderer, Brunsø, Bredahl and Grunert (2004) observed that social relationships that emerge from family members and friends both at home and outside tend to shape people attitude towards food waste. For instance, during special celebrations such as Ramadan, many Muslims with the expectation to meet the requirements of the Muslim tradition are most likely to cook more food than required. Accordingly, the eating pattern that changes during times of Ramadan influence consumer attitude toward food waste.

Likewise, in the study of Odabasi and Argan (2009) social norm mediated the relationship perceived food quality and attitude towards food quality. Consistent result is produced in the study of Karim Ghani, Rusli, Biak and Idris (2013) as the inclusion of other variables such as perceived behavioural control and subjective norm mediated the relationship between perceived food quality and consumer attitude towards food waste. Specifically, in the study of Karim Ghani et al. (2013), these two variables predicted 13.7 per cent of the variance in the consumer attitude towards food waste. Russell et al. (2017) affirmed similar mediation effect between subjective norm and perceived behavioural control consumer attitude towards food waste. Again, in the study of Tsai et al. (2020), 
perceived behavioural control had a significant mediating effect on consumer attitude towards food waste. However, in the same study, subjective norm had no mediating effect on the respondents' attitude towards food waste suggesting that the subjective norm which come from influence from important people such as family members, friends and colleagues did not in any way influence the respondents' attitude towards food waste. Tsai et al. (2020) attributed this insignificant relationship to the caliber of their sample that is, made up of young and independent individuals.

\section{Conceptual Framework: The Theory of Planned Behaviour}

This concept was proposed by Icek Ajzen in 1991. The theory is usually applied to health and food related behaviours and it links one's beliefs and behaviour (Kim, Njite \& Hancer, 2013; Stancu et al. 2016). The concept of this work is adapted from the constructs of the Theory of Planned Behaviour, thus, attitude, subjective norms and perceived behavioural control. The TPB further proposes that the strength of each of the antecedent merges into a part of the person's intention to exhibit a certain behaviour. A person's attitude is formed by his or her favourable or unfavourable judgement about a given behaviour and it is actually a mindset. In connection with food waste, attitude is about whether people assume if it is a critical issue that deserves to be reduced. A consumer's attitude of eating everything up on a plate is either acceptable or not acceptable. Thus, in a case of food waste, the important issue then has to do with whether people accept if it is a significant issue. Research has proven that consumers feel "bad" and are worried about discarding food and this gives an indication that consumers have a negative attitude towards that behaviour (Abeliotis et al., 2014; Evans, 2012; Watson \& Meah, 2012).

Subjective norms refer to the belief about whether most people approve or disapprove consumers behaviour, thus, the social pressure one feels to complete (or not complete) a given behaviour (van der Werf et al., 2019). That is, how people behave can possibly be influenced by society's expected behaviour (Graham-Rowe et al., 2015).

Consumers' perception of food quality impacts food waste. Sadilek (2019) suggests that consumers have different perspective from which food quality is assessed. Sensorial attributes such as taste, flavour, colour, texture and overall acceptability would influence food choice and consequently impact food waste. With the improvement in the quality of meals, consumers are likely to consume more and less waste is generated. Food is likely to be discarded when the quality is substandard, especially with regards to the sensorial attributes (Evans, 2011). Accordingly, the main concepts this study seeks has investigate is graphically represented in Figure 1

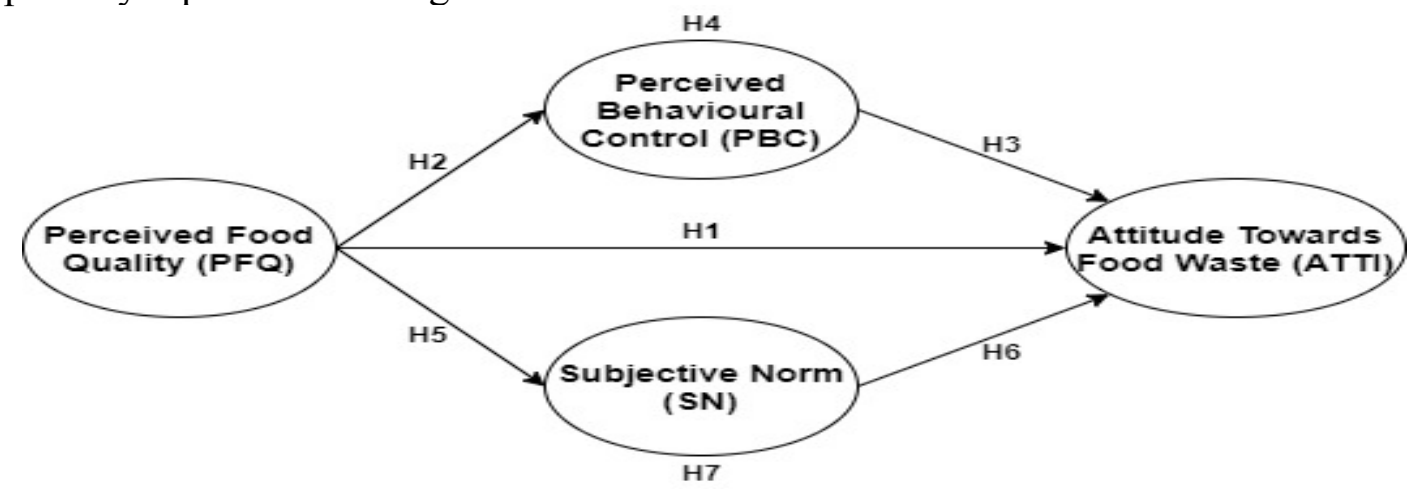

Figure 1: Conceptual Framework 


\section{Research Design}

\section{Materials and Methods}

A research according to Creswell (2014) is a strategy or plan or structures for conducting research work. He further indicated that the selection of the design for a study depends on the researchers' agenda, nature of research, the problem to be addressed, and the researchers' personal experiences. A descriptive research of the survey design was used in this study. Descriptive survey deals with the collection of data to answer questions or test hypotheses concerning the present status of the subject being studied. Descriptive survey can either be sample or census survey. In a sample survey, information is collected on a population and some generalization is made about the entire population. On the other hand, a census survey is where an attempt is made to acquire data from each and every member of the population under study. The researcher employed the base line sample survey for the study because of its suitability. This enabled the researcher to describe certain aspects of the population by sampling individuals to complete a set of questionnaires. As the subjects of the sample have the same characteristics as the population. A generalization was made about the whole population based on the responses of the sample drawn from the population.

\section{Population for the Study}

A target population is any indefinable total set of elements about which the researcher wishes to make inferences (Collis \& Hussey, 2009). In order to achieve the objectives of this research, the research population was chosen to include all Senior High Schools students and matrons in the Kumasi Metropolis. This population was suitable as it consists of individuals who are directly involved in food consumption and its wastage. In all, there are thirteen (13) Senior High Schools in the Kumasi Metropolis, five (5) single sex school and eight (8) mixed schools.

\section{Sampling and Sample Techniques}

The study used a multi-stage cluster sampling technique in selecting the study participants. According to Alvi (2016), multi-stage cluster sampling becomes very useful sampling approach to use particularly when a study has a large population scattered across different clusters in this case boys' schools, girls' schools and mixed sex school. As indicated in the study population, the Kumasi Metropolis has a total of thirteen (13) Senior High Schools in the Kumasi Metropolis, with three of these schools as girls' school, two as boys' schools and eight as mixed-sex schools. Hence, with these different clusters within the population, it becomes unfeasible to use a simple random sample to select the participating schools since it may not yield into a good representation of the exact Senior High Schools within the Kumasi Metropolis. Accordingly, the population were divided into three groups namely; girls' school, boys' school and mixed sex school. Accordingly, schools within these categories were put into separate containers and randomly shuffled to select one school from each category (i.e. girls' school, boys' school and mixed sex school).

From this exercise, Opoku Ware school was selected from the boys' school category, Kumasi Girls School was selected from the girls' school category and Osei Kyeretwie Senior High was selected from the mixed sex school category. At the time of the study, there were only form two students at school due to the Covid-19 pandemic hence, the student's population entirely came solely from form two students. Opoku Ware had a form two boarding population of 1603, Osei Kyeretwie Senior High had a form two boarding students' population of 1166 and lastly Kumasi Girls School had a form two 
boarding students' population of 925 . However, to determine the sample size for each of these schools, the study used the Krejcie and Morgan (1970) sampling size determination table. Based on the sampling table for the study, Opoku Ware with a population of 1603 had a corresponding sample size of 310 , Osei Kyeretwie Senior High with a population of 1166 had a corresponding sample size of 291 and finally Kumasi Girls School with a boarding population of 925 had a corresponding sample size of 274 . Afterwards, in each of these schools the identified sample size were randomly selected from the schools' form two students.

Table 1: Description of Population Size and Sample Size

\begin{tabular}{lcc}
\hline $\begin{array}{l}\text { Cluster of Sample of Customers along } \\
\text { the different schools }\end{array}$ & Population size & Sample size \\
\hline $\begin{array}{l}\text { Opoku Ware school for boys' school } \\
\text { Kumasi Girls Senior High for girls' }\end{array}$ & 1603 & 310 \\
school category & 925 & 274 \\
$\begin{array}{l}\text { Osei Kyeretwie Senior High for mixed } \\
\text { school category }\end{array}$ & 1166 & 291 \\
Total & 3694 & 875
\end{tabular}

Instrument for Data Collection

A mixed method approach was employed for this study. According to Honorene (2017), a mixed method approach combines different aspects of research methods and thus increase the validity and the credibility of the data set and information used. Questionnaire, interview as well as an observation checklist were used to collect the data. Using multiple methods help facilitate deeper understanding and help to overcome the weakness or intrinsic biases and the problems that come from a single method (Honorene, 2017).

\section{Observation}

An observation schedule was designed that lists the factors for observation (see appendix). Observation was carried out on physical aspects and on processes. The food preparation process was observed to understand what, how and why food management practices are carried out in the kitchen. After all students were served, an observation of the kitchen and serving pans were also inspected, to know the amount and type of unserved foods and plate leftovers. The state of the dining hall, the serving process, eating process, students and plates were observed to pick out the factors and reasons for contributing to plate waste. Finally, observation of food waste containers was done to get an idea of the amount and types of food wasted.

\section{Questionnaire}

Data for the questionnaire was collected via structured questions consisting of close ended questions. Questionnaires were used as the data collection instrument due to its ability to collect data of high quality within the shortest possible time with minimum costs as well as not requiring the physical presence of the researcher (Robertson and McCloskey, 2002). The questions were grouped according to the constructs. Some aspects of the questionnaire were adopted from the study of van der Werf et al. (2019) to ensure the reliability of the instruments. 


\section{Questionnaire and Measures}

The study was based on 1 dependent variable (Attitude towards food waste - ATTI), 2 mediators (Perceived Behavioral Control - PBC; and Subjective Norm - SN), and 1 independent variable (Perceived Food Quality - PFQ). Attitude was conceptualized as the positive or negative evaluations of self-performance of a specific behaviour (Aktas et al., 2018). Perceived behavioral control was conceptualized as the perceived ease or difficulty of behaving in a specific way (Aktas et al., 2018). Subjective norm was conceptualized as the perception of social pressures or relevant others' belief that one should or should not behave in a specific way (Aktas et al., 2018). Perceived food quality was conceptualized as a consumer personal assessment about a product or service overall quality or dominance. Parasuraman et al., 2005). These 5 main variables were all measured on a Likert scale of 1Strongly disagree to 7-Strongly agree. The study controlled for some other demographic variables. Although these are not the main variables of interest, researchers such as Dogbe et al. (2020) have suggested that including control variables in a study is important because of their potential influence on outcome of the study (analysis). This study controlled for 5 variables, which were gender of students, age of student, track or intake, amount of stipend received, and the frequency of receiving the stipend. Gender was coded as $0=$ Female and $1=$ Male, whiles Track was coded as $0=$ Green and $1=$ Gold.

\section{Data Analysis}

The data was analysed using Structural Equation Modeling (SEM) approach in Amos (v.25) to test the relationships among the constructs in the proposed model. SEM- approach in Amos (v.25) was seen as most suitable because of the predictive focus of the objective of the study (Malkanthie, 2015). Again, SEM- approach in Amos (v.25) due to its distributionfree assumption which was suitable for the study objectives. The responses collected from the three categories of schools (mixed, boys' and girls'), the dominant data type is mostly represented categorically for the various responses while the rest were spread among continuous data (age, gender and stipend) and other information about the respondent's profile.

\section{Reliability and Validity of the Constructs}

As part of the validity and reliability checks, this study conducted Confirmatory Factor Analysis (CFA) in Amos (v.23), using maximum likelihood to assess how well the data fit our model (results presented in Table 2). During the CFA analysis, measurement items which loaded poorly (less than 0.5 ) were deleted from the final analysis. Originally, attitude had 7 measurement items, but 4 were retained. Perceived food quality had 9 measurement items, but 6 were retained. Perceived behavioural control and subjective norm however, had all their respective 4 measurement items retained. To further check for reliability (internal consistency) of the measurement items, Cronbach's Alpha (CA) analysis was run using the retained measurement items. To achieve internal consistency, the alpha score is expected to be at least 0.7 , which was achieved for all constructs in this study (Table 2). Convergence validity was also assessed by checking the Average Variance Extracted (AVE) for the constructs. To achieve convergence validity, AVE score should be at least 0.5, and Composite reliability (CR) should also be at least 0.7 (Fornell and Larcker, 1981). From the results presented, the least AVE was 0.568 (PBC) and the least CR was 0.839 (PBC), implying that convergence validity was achieved for this study. Based on Hair et al.'s (2010) recommended fit indices criteria, we also conclude that our CFA model for the constructs appropriately fit the data. CMIN/DF is supposed to be less than 3, CFI is 
all expected to be greater than 0.9, whiles RMSEA and SRMR are also expected to be less than 0.08 . P-Close is also expected to be statistically insignificant at $5 \%$. These were all achieved as presented in Table 2. Figure 2 presents the CFA in a diagrammatic form

\section{Ethical Consideration}

Easterby-Smith et al., (2018) suggest that researchers should all the time protect the interest of the research subject and their integrity guaranteed. Research ethics as stated by Bryman and Bell (2007) is the protection of the participants' privacy and anonymity, while being transparent about how the data will be utilized by the researcher. The respondents and participants were informed and provided with information concerning the purpose of the research and what their answers would be used for (only for the purpose of the research). The respondents and participants were informed that their names would be classified and that their age and gender would only be required.

\section{Results and Discussion}

\section{Results}

The study focused on 301 students selected from second cycle schools in the Kumasi Metropolis. Data was gathered using a structured questionnaire, and respondents were selected using simple random sampling technique. From the respondents selected, 157 were males whiles 144 were females. About $95 \%$ of the respondents were aged 13-20 years, with only $5 \%$ whose age was over 20 years. There were two tracks (intakes) of students, the green (first semester begins September) and the gold (first semester begins November). This study had 188 green track students and 113 gold track students. Most of the students sampled received less than GHC150 per semester, and the majority of the students (135 students) also received their allowances on monthly basis.

Table 2: Demographics of Students

\begin{tabular}{lcc}
\hline Demographics & Frequency $(\mathbf{N})$ & Percentages $(\%)$ \\
\hline Gender & $\mathbf{3 0 1}$ & $\mathbf{1 0 0 . 0}$ \\
\hline Male & 157 & 52.2 \\
Female & 144 & 47.8 \\
\hline Age & 301 & $\mathbf{1 0 0 . 0}$ \\
\hline $13-15$ years & 47 & 15.6 \\
16-19 years & 239 & 79.4 \\
Above 20 years & 15 & 5.0 \\
\hline Track & $\mathbf{3 0 1}$ & $\mathbf{1 0 0 . 0}$ \\
\hline Green & 188 & 62.4 \\
Gold & 113 & 37.5 \\
\hline Stipend (GHC) & 301 & $\mathbf{1 0 0 . 0}$ \\
\hline $20-50$ & 75 & 24.9 \\
$51-100$ & 129 & 42.8 \\
$101-150$ & 67 & 22.3 \\
151-200 & 18 & 6.0 \\
$201-300$ & 7 & 2.3 \\
Above 300 & 5 & 1.7 \\
\hline Frequency of Receiving Stipend & $\mathbf{3 0 1}$ & $\mathbf{1 0 0 . 0}$ \\
\hline Weekly & 47 & 15.6 \\
Two weeks & 69 & 22.0
\end{tabular}


Three weeks

Table 3 Confirmatory Factor Analysis

\begin{tabular}{lc}
\hline Model Fit Indices: $C M I N=170.729 ; D F=121 ; C M I N / D F=1.411 ; C F I=.975 ; T L I=$ & $\begin{array}{c}\text { Std. } \\
\text { Factor } \\
\text { Loading }\end{array}$ \\
\hline $969 ; R M R=.032 ; R M S E A=.037 ; P C l o s e=.959$ & 0.736 \\
\hline Perceived Food Quality (PFQ): CA=0.866; CR=0.904; AVE=0.612 & 0.844 \\
\hline I like the taste of foods served (QUAL1) & 0.842 \\
I like the appearance of foods served (QUAL2) & 0.722 \\
I like the texture of food served (QUAL3) & 0.733 \\
I like the flavour of foods served (QUAL4) & 0.805 \\
The temperature at which food is served is excellent (QUAL5) & \\
I am satisfied with the cleanliness of the table on which food is served (QUAL6) & 0.776 \\
\hline Perceived Behavioural Control (PBC): CA=0.843; CR=0.839; AVE=0.568 & \\
\hline I find it difficult to eat all my food because I don't usually feel hungry during meal & \\
time (PERC1) & 0.763 \\
I find it difficult to finish my food because I don't get enough time to eat all of my & \\
food (PERC2) & 0.640 \\
I find it difficult to make sure that all my food served is eaten completely (PERC3) & 0.823 \\
I have the feeling that I cannot do anything about the food wasted in the dining hall & 0.823 \\
(PERC4) &
\end{tabular}

\section{Subjective Norms (SN): $\mathrm{CA}=0.849 ; \mathrm{CR}=0.856 ; \mathrm{AVE}=0.601$}

I don't eat food completely because my colleagues don't also eat all their food (SUBL1)

A lot of my friends disagree when I try to reduce food waste at the dining hall (SUBJ2)

People who are important to me find my attempts to reduce the amount of food wasted unnecessary (SUBJ3)

It would be embarrassing to me if I finish all the food served to me that a lot people do not like (SUBJ4)

\section{Attitude Towards Food Waste (ATTI): $\mathrm{CA}=0.872 ; \mathrm{CR}=0.844 ; \mathrm{AVE}=0.576$}

It is wrongful to have a plate left over (ATT1)

It is not a good practice to discard food while other people in the world are in need of it (ATT2)

Table 4. Discriminant Validity and Descriptive Analysis

\begin{tabular}{lllllll}
\hline Variables & Mean & Std. Dev. & PFQ & PBC & SN & ATTI \\
\hline PFQ & 3.349 & 1.438 & $\underline{\mathbf{0 . 7 8 2}}^{* *}$ & & & \\
PBC & 4.333 & 1.571 & $0.323^{* *}$ & $\underline{\mathbf{0 . 7 5 4}}^{* *}$ & & \\
SN & 4.427 & 1.239 & $0.455^{* *}$ & $0.483^{* *}$ & $\underline{\mathbf{0 . 7 7 5}}^{* *}$ & \\
ATTI & 5.400 & 1.117 & $0.407^{* *}$ & $0.321^{* *}$ & $0.542^{\mathbf{0 . 7 6 0}}$ \\
\hline
\end{tabular}

$* * \sim P$-value significant at $1 \%(0.01)$

$\sqrt{ }$ AVE are bold and underlined

Table 4 presents the discriminant validity and the descriptive statistics on the variables studied. Attitude had the highest mean score of 5.4/7, whiles perceived food quality had the 
least mean score of 3.349/7. Discriminant validity was assessed by comparing the squaredroot of the AVEs (VAVEs) with the inter-correlation scores. To achieve discriminant validity, the least $\sqrt{ }$ AVE should be greater than the largest correlation score (Bamfo et al., 2018). From the analysis, the least $\sqrt{ }$ AVE was 0.754 , which was greater than the largest correlation score of 0.542 . This indicates the study achieved discriminant validity.

\section{Path Way Summary}

Structural Equation Modelling (SEM) was run in Amos (v.23) to assess the various paths hypothesized in the study. Age, stipend, frequency of receiving stipend (REG), and track (as control variables) had a negative effect on student's attitude towards food waste (ATTI). However, only stipend received had a significant effect on students' attitude towards food waste. The negative coefficient implies that students who received more stipend (GHC) had less favourable attitude towards food waste, while students who received less stipend had more positive attitude towards food waste. This was quite expected, as students with more stipend (money) could afford to buy foods outside the dining hall, so they did not care much when food was wasted. Gender had a significant positive effect on students' attitude towards food waste. Gender was coded $0=$ female and $1=$ male. The positive coefficient therefore implies that male students had more favourable attitude towards food waste, compared to female students.

Results on the hypothesized paths indicate that perceived food quality (PFQ) had a significant positive effect on attitude towards food waste $(\beta=0.509 ; C . R .=5.222)(\beta=$ 0.509; C.R = 5.222). Meaning students who perceived the dining hall meals as of high quality, have a more favourable attitude towards food waste, and vice versa. Perceived bahavioural control (PBC) had a significant positive effect on students' attitude towards food waste $(\beta=0.418 ; C . R .=4.274)(\beta=0.418 ; \mathrm{C} . \mathrm{R} .=4.274)$. Implying that high level of perceived behavioural control leads to more positive attitude towards food waste, and vice versa. Similarly, subjective norms $(\mathrm{SN})$ also had a significant positive effect on attitude towards food waste $(\beta=0.429 ; C . R .=5.151)(\beta=0.429 ;$ C.R. $=5.151)$. That is, high level of subjective norm leads to more positive attitude towards food waste, and vice versa. Students' perceived food quality also had a significant positive effect on perceived behavioural control $(\beta=0.318 ; C . R .=5.286)(\beta=0.318 ; C . R=5.286)$ and subjective norm $(\beta=0.462 ; C . R .=6.259)(\beta=0.462 ;$ C.R. $=6.259)$. High perceived food quality therefore increases perceived behavioural control and subjective norms of students, and vice versa. Just like the CFA, the structural model as presented in Table 5 also met the various fit indices as proposed by Hair et al. (2010). Figure 3 presents the structural model for the study. 
Table 5 Path Summary

\begin{tabular}{|c|c|c|}
\hline Path & Std. Estimate & C.R. \\
\hline GENDER $\rightarrow$ ATTI & 0.193 & $1.997^{*}$ \\
\hline $\mathrm{AGE} \rightarrow \mathrm{ATTI}$ & -0.021 & -1.053 \\
\hline $\mathrm{STIP} \rightarrow \mathrm{ATTI}$ & -0.202 & $-2.393^{*}$ \\
\hline $\mathrm{REG} \rightarrow \mathrm{ATTI}$ & -0.091 & -1.299 \\
\hline TRACK $\rightarrow$ ATTI & -0.068 & -1.201 \\
\hline $\mathrm{PFQ} \rightarrow \mathrm{ATTI}$ & 0.509 & $5.222^{* *}$ \\
\hline $\mathrm{PBC} \rightarrow \mathrm{ATTI}$ & 0.418 & $4.274^{* *}$ \\
\hline $\mathrm{SN} \rightarrow \mathrm{ATTI}$ & 0.429 & $5.151^{* *}$ \\
\hline $\mathrm{PFQ} \rightarrow \mathrm{PBC}$ & 0.318 & $5.286^{* *}$ \\
\hline $\mathrm{PFQ} \rightarrow \mathrm{SN}$ & 0.462 & $6.259^{* *}$ \\
\hline \multicolumn{3}{|c|}{$\begin{array}{l}\text { Model Fit Indices: } C M I N=460.905 ; D F=217 ; C M I N / D F=2.124 ; C F I= \\
.929 ; T L I=.921 ; R M R=.034 ; R M S E A=.061 ; \text { PClose }=.079\end{array}$} \\
\hline
\end{tabular}

\section{Mediating Effect}

The study also assessed the mediating effects of perceived bahvioural control and subjective norms in the relationship between perceived food quality and attitude towards food waste. Table 6 presents the direct and indirect (mediating) effects. The indirect effect of perceived food quality on attitude towards food waste, through perceived behavioural control, was 0.133. This coefficient was statistically significant, using the Sobel's test approach. This implies that, the effect of perceived food quality on students' attitude towards food waste was not just direct, but partially mediated through perceived bahvioural control. In other words, perceived bahvioural control partially explains the effect on perceived food quality on attitude towards food waste. The study also assessed the potential of subjective norms in explaining the effect of perceived food quality on students' attitude towards food waste. Results from Table 6 indicate that the indirect effect of perceived food quality through subjective norm was 0.198 , which was statistically significant (using the Sobel's test). That is, the effect of perceived food quality on attitude towards food waste was not only direct, but partially mediate through subjective norms. That is, subjective norm significantly explained the effect on perceived foods quality on attitude towards food waste among second cycle students in Ghana.

\section{Table 6 Mediating Effect}

\begin{tabular}{|c|c|c|c|c|c|c|c|c|}
\hline \multirow{3}{*}{ Paths } & & & \multicolumn{4}{|c|}{ Indirect Paths } & \multirow{3}{*}{$\begin{array}{l}\text { Indirect } \\
\text { Effect } \\
\left(a^{*} b\right)\end{array}$} & \multirow{3}{*}{$\begin{array}{l}\text { Sobel' } \\
\text { s Test }\end{array}$} \\
\hline & \multicolumn{2}{|c|}{ Direct Effect } & \multicolumn{2}{|l|}{$A$} & \multicolumn{2}{|l|}{$B$} & & \\
\hline & Est. & C.R. & Est. & C.R. & Est. & C.R. & & \\
\hline $\mathrm{PFQ} \rightarrow \mathrm{PBC} \rightarrow \mathrm{ATTI}$ & 0.509 & $5.222^{* *}$ & 0.318 & $5.286^{* *}$ & 0.418 & $4.274^{* *}$ & 0.133 & $3.324^{* * *}$ \\
\hline $\mathrm{PFQ} \rightarrow \mathrm{SN} \rightarrow \mathrm{ATTI}$ & 0.509 & $5.222^{* *}$ & 0.462 & $6.259^{* *}$ & 0.429 & $5.151^{* *}$ & 0.198 & $3.977^{* * *}$ \\
\hline
\end{tabular}

${ }^{* *}$ Sig. at $1 \%$

\section{Discussion}

Results from the study suggest that age, stipend, frequency of receiving stipend (REG), and track (as control variables) had an inverse effect on student's attitude towards food waste (ATTI). Specifically, stipend recorded a significant negative effect on students' attitude towards food waste. This suggests that as the students' stipend increases, their penchant to 
engage in food waste increases in the same direction as they now have what it takes to purchase more food than what they actually need.

Results from the study revealed that perceived food quality (PFQ) had a significant positive effect on a respondent attitude towards food waste $(\beta=0.509 ; C . R .=5.222)(\beta$ $=0.509$; C.R. $=.5 .222$ ). Meaning students who perceived the dining hall meals as of high quality, have a more favourable attitude towards food waste, and vice versa. In order words, students' perception of the meal quality provided at the dining hall will predict their attitude as to whether they will waste the food been served or not. Accordingly, results from this study align with the recent conclusion of Mijares et al. (2020) as their study posited a significant relationship between perceived food quality and respondent attitude towards food waste. Again, results from this study corroborate the conclusion of Conrad et al. (2018) as their results reported a significant relationship between perceived food quality and an individual attitude towards food waste. Similarly, the results established in this study align with the observation of Schiavone et al. (2020) as in their study it was realized that consumers who had low expectation about the quality of food provided them threw a significant part of their food away than customers who had positive expectation about the quality of food provided.

Perceived bahavioural control $(\mathrm{PBC})$ reported a significant positive effect on students' attitude towards food waste $(\beta=0.418$; C.R. $=4.274)$. This implies that high level of perceived behavioural control leads to more positive attitude towards food waste, and vice versa. Generally, students who may perceive food waste as a less difficult task to do or a pleasant thing to do are more likely to have negative attitude towards food waste than students who may regard the act as a very difficult task to do or less pleasant to do. Accordingly, a student perceive behavioural control will directly shape a student attitude towards food waste. As demonstrated in this study, PBC posited a significant positive relationship on the respondents' attitude towards food waste suggesting that in this context, most of the respondents' regard food waste as a pleasant act to do and again saw it as an act that came with no stress or exhaustion. On this score, results from the study concur with the works of Tsai et al. (2020) and Stancu et al. (2016) as their results established a significant relationship between PBC and the respondents attitude towards food waste. Results from this study also confirm with the results of van der Werf and Seabrook (2019) as their work posited a significant relationship between $\mathrm{PBC}$ and respondents attitude towards food waste.

Some authors hold the view that food waste behaviours are often times very difficult to be easily seen by other people particularly, neighbours or friends than probably pro-environmental behaviours (e.g., reusing or transport behaviours), the social normative movers of food waste behaviour are most likely to have less effect in shaping a person food waste behaviour (Quested et al., 2011). In this study, subjective norm (SN) recorded a significant positive effect on the respondents' attitude towards food waste $(\beta=0.429$; C.R. $=5.151)$. That is, high level of subjective norm leads to more negative attitude towards food waste, and vice versa. The significant relationship established between subjective norm and the students' attitude towards food waste could be possibly linked to the context with which this study was undertaken that is, a boarding school. Generally, in boarding schools, meals are served in a dining hall and eat together by all the students in the dining hall. Hence, students see the actions and attitude of their colleagues, seniors and school prefects with regards to food waste. This direct viewing of their colleagues, seniors and school prefect's food waste acts and attitude will directly shape the rest of the students' food waste behaviour. The result from this study is consistent with the results of van der 
Werf and Seabrook (2019) as subjective norm reported a significant influence on the respondents attitude towards food waste. However, results from this study could not affirm the conclusions of Quested et al. (2013) and Stefan et al. (2013) as in their study, subjective norm reported no significant influence on consumers attitude towards food waste. Again, the respondents perceived food quality had a significant positive effect on perceived behavioural control $(\beta=0.318 ;$ C.R. $=5.286)$ and subjective norm $(\beta=0.462$; C.R. $=6.259)$. Meaning, the respondents' perception about the quality of meal provided to them at the dining hall influenced their PBC (i.e. the extent of ease or difficulty with which a consumer perceives food waste) as well as influenced the subjective norm and these two behavioural determinants had an influence on their food waste attitudes This result is in line with the earlier works of Hasana et al. (2015), Stancu et al. (2016) and Rusell et al. (2017) as their results observed a significant positive effect between perceived food quality, perceived behaviour control and subjective norm.

The indirect effect of perceived food quality on the students' attitude towards food waste, through perceived behavioural control, was 0.133 . This coefficient was statistically significant, using the Sobel's test approach. This hints that, the effect of perceived food quality on students' attitude towards food waste was not just direct, but partially mediated through perceived behavioural control. In other words, perceived behavioural control partially explains the effect on perceived food quality on attitude towards food waste. Also, when it comes to the mediating effect subjective norm had on the relationship between perceived food quality and student attitude towards food waste, it was established that the indirect effect of perceived food quality through subjective norm was 0.198 , which was statistically significant (using the Sobel's test). That is, the effect of perceived food quality on attitude towards food waste was not only direct, but partially mediated through subjective norms. That is, subjective norm significantly explained the effect on perceived foods quality on attitude towards food waste among second cycle students in Ghana. As argued by Mondéjar-Jiménez et al. (2016) the differences in individual food waste behaviour is partially or fully explained by other cofounding factors. For instance, Scholderer et al. (2004) argued that the social relationships that emerge from family members and friends both at home and outside home tend to shape people attitude towards food waste. Similarly, in this study, perceived behavioural control and subjective norm mediated the relationship between perceived food quality and students' attitude towards food waste. Again, results from this study affirm the study of Odabasi and Argan (2009) as per their results, social norm mediated the relationship between perceived food quality and respondents' attitude towards food quality. Results in this study is once again consistent with that of Karim Ghani et al. (2013) as their inclusion of other variables such as perceived behavioural control and subjective norm in their variables were found to have partial mediation effect on the relationship between perceived food quality and consumer attitude towards food waste.

\section{Conclusion}

Students' attitude towards food waste are shaped by both personal factors such as age, gender, stipend and regularity of stipend received and behavioural factors factors. Particularly, in the case of age, it recorded a significant inverse relationship on the students' attitude towards food waste. Stipend also posited a significant relationship on the students' attitude towards food waste. This implies that as a person stipend increases, their penchant to engage in food waste increase in the same direction as they now have what it takes to purchase more food than what they can actually consume leading to the rejection of the dining hall meals. On gender, male students had more favourable attitude towards 
food waste, compared to their female counterparts indicating that a person' gender had a significant influence on their attitude toward food waste. The behavioural factors, perceived bahavioural control (PBC), subjective norm and perceived food quality reported a positive effect on students' attitude towards food waste. It was established that the relationship between perceived food quality and students' attitude towards food waste was partially mediated by perceived behavioural control and subjective norm.

\section{Limitations}

The study samples came from only three schools in the Kumasi Metropolis and for this reason results from the study will not be a representative of all the Senior High in the Kumasi Metropolis schools in Ashanti Region and Ghana at large. A more comprehensive sample is required for the findings of this research to be generalized.

\section{Further Research}

The course or programme of study of students is hypothetical perceived to partially inform students about food waste. Science and Home Economics programmes are perceived to better inform students about food waste management than other courses. Hence, future studies can examine possible moderating role of programme of study in the linkage between behavoural determinants and food waste intention of students. Besides, this study can also be replicated in many different canteen settings encountering challenges of food waste behaviour like the restaurants, hospitals and many other organizations in Ghana. Thus, future studies can look at food waste intention of consumers and the determinant factors in these sectors. Again, future research can be conducted in quantifying the production of food waste in Senior High Schools. Future research can again look at interventions to mitigate food waste in Senior High Schools.

\section{References}

Abeliotis, K., Lasaridi, K., \& Chroni, C. (2014). "Attitudes and Behaviour of Greek Households Regarding Food Waste Prevention." Waste Management \& Research 32 (3): 237-240.

Affognon, H., Mutungi, C., Sanginga, P., \& Borgemeister, C. (2015). Unpacking postharvest losses in Sub-Saharan Africa: a meta-analysis. World Dev. 66, 49-68.

Ajzen, I. (1991). The theory of planned behavior. Organizational Behavior and Human Decision Processes 50(2): $179-211$.

Bamfo, B. A., Dogbe, C. S. K., \& Mingle, H. (2018). Abusive customer behaviour and frontline employee turnover intentions in the banking industry: The mediating role of employee satisfaction. Cogent Business \& Management, 5(1), 1-15.

Beretta, C., Stoessel, F., Baier. U., \& Hellweg.S., (2013). Quantifying food losses and the potential for reduction in Switzerland. Waste Manage. (Oxford) 33 (3), 764-773).

Conrad, Z., Niles, M., Neher, D., Roy, E., Tichenor, N., \& Jahns, L. (2018). Relationship between food waste, diet quality, and environmental sustainability. PLOS ONE, 13(4): e0195405. https:// doi.org/10.1371/journal.pone.0195405, 1-18.

Dogbe, C. S. K., Tian, H., Pomegbe, W. W. W., Sarsah, A. S., \& Otoo, C. O. A. (2020). Effect of network embeddedness on innovation performance of small and mediumsized enterprises: The moderating role of innovation openness. Journal of Strategy and Management, 13(2), 181-197. 
Evans, D. (2011). Blaming the Consumer --- Once Again: the social and material contexts of everyday food waste practices in some English households. Critical Public Health 21(4):429-440.

Evans, D. (2012). "Beyond the Throwaway Society: Ordinary Domestic Practice and a Sociological Approach to Household Food Waste." Sociology 46 (1): 41-56. doi:10.1177/0038038511416150. http://soc.sagepub.com/cgi/doi/10.1177/0038038511416150.

FAO (2013). Food wastage footprint: Impacts on natural resources. Summary report. Available online: http://www.fao.org/3/i3347e/i3347e.pdf .

FAO (2014). Food Wastage Footprint: Full Cost-Accounting. FAO, Rome.

Farr-Wharton, G., Foth, M., \& Choi, H.J. (2014). "Identifying Factors That Promote Consumer Behaviours Causing Expired Domestic Food Waste." Journal of Consumer Behaviour 13 (6): 393-402.

Ghana Web (2017). https://www.ghanaweb.com/pages/local/news/201710/331500.php.

Graham-Rowe, E., Jessop, D.C., \& Sparks, P. (2015). "Predicting Household Food Waste Reduction Using an Extended Theory of Planned Behaviour." Resources, Conservation and Recycling 101: 194-202.: 10.1016/j.resconrec.2015.05.020. http://linkinghub.elsevier.com/retrieve/pii/S092134491530015X.

Graham-Rowe, E., Jessop, D.C., \& Sparks, P. (2019). Self-affirmation theory and proenvironmental behaviour: Promoting a reduction in household food waste. Journal of Environmental Psychology 62, 124-132.

Hair, J. F., Black, W. C., Babin, B. J., \& Anderson, R. E. (2010). Multivariate Data Analysis: A Global Perspective (7th Ed.). Pearson Education, Upper Saddle River, NJ.

Kim, Y. J., Njite, D., \& Hancer, M. (2013). Anticipated emotion in consumers' intentions to select eco-friendly restaurants: Augmenting the theory of planned behavior. International Journal of Hospitality Management, 34, 255-262.

Karim Ghani, W., Rusli, I., Biak, D., \& Idris, A. (2013). "An application of the theory of planned behaviour to study the influencing factors of participation in source separation of food waste". Waste Management, 33(5), doi: 10.1016/J, 1276-1281.

Marx, A. (2015). The State of Food Insecurity in the World: Meeting the 2015 International Hunger Targets: Taking Stock of Uneven Progress. FAO, IFAD and WFP. doi: I4646E/1/05.15. http://www.fao.org/3/a4ef2d16-70a7-460aa9ac2a65a533269a/i4646e.pdf

Mijares, V., Alcivar, J., \& Palacios, C. (2020). Association Between Diet Quality and Food Waste in South Florida. Current Developments in Nutrition, 143-145.

Molnar, P. (1995). A model for overall description of food quality. Food Qual. Prefer., 6, $185-190$.

Mondéjar-Jiménez, J.-A., Ferrari, G., Secondi, L., \& Principato, L. (2016). "From the table to waste: an exploratory study on behaviour towards food waste of Spanish and Italian youths". Journal of Cleaner Production, 138, doi: 10.1016/J.JCLEPRO.2016, 8-18.

Odabasi, Y., \& Argan, M. (2009). "Aspects of underlying Ramadan consumption patterns in Turkey". Journal of International Consumer Marketing, 21(3), 203-218.

Parasuraman, A., Zeithaml, V. A., \& Malhotra, A. (2005). E-SERVQUAL: A multipleitem scale for assessing electronic service quality. Journal of Service Research, $7(X), 1-21$. 
Parfitt, J., Barthel, M., \& Macnaughton, S. (2010). Food waste within food supply chains: quantification and potential for change to 2050 Philosophical Transactions of the Royal Society B: Biological Sciences 365 3065-81.

Priefer, C., Jorissen, J., \& Brautigam, K. (2016). Food waste prevention in Europe - A cause-driven approach to identify the most relevant leverage points for action . Resour. Conserv. Recy. 109, 155-165.

Quested, T. E., Marsh, E., Stunell, D., \& Parry, A. (2013). "Spaghetti Soup: The Complex World of Food Waste Behaviours." Resources, Conservation and Recycling 79: 43-51

Russell, S., Young, C., Unsworth, K., \& Robinson, C. (2017). Bringing habits and emotions into food waste behaviour. Resources, Conservation \& Recycling, 125 , $107-114$.

Sadilek, T. (2019). Perception of Food Quality by Consumers: Literature Review European Research Studies Journal Volume XXII, Issue 1, 2019 pp. 52-62

Scholderer, J., Brunsø, K., Bredahl, L., \& Grunert, K. (2004). "Cross-cultural validity of the Food-Related Lifestyles instrument (FRL) within Western Europe". Appetite, 42(2), 197-211.

Schiavone, S., Pistone, M., Finale, E., Guala, A., \& Attena, F. (2020). Patient Satisfaction and Food Waste in Obstetrics and Gynaecology Wards. Patient Preference and Adherence, 14 , 1381-1388.

Stancu, V. Haugaard, P., \& Lähteenmäki, L. (2016). "Determinants of Consumer Food Waste Behaviour: Two Routes to Food Waste." Appetite in press, doi: 10.1016/j.appet.2015.08.025. http://www.sciencedirect.com/science/article/pii/S0195666315003992.

Starovoytova, D., \& Namango. S. (2018). "Solid Waste Management (SWM) at a University Campus (Part 7/10): Food Waste and Preliminary Design of Aerobic Composter Journal of Environment and Earth Science

Stefan, V., van Herpen, E., Tudoran, A. A., \& Lahteenmaki, L. (2013). Avoiding food waste by Romanian consumers: the importance of planning and shopping routines. Food Quality and Preference, 28(1), http://dx.doi.org/10.1016/j.foodqual.2012.11.001,375-381.

Tsai, W., Chen, X., \& Yang, C. (2020). Consumer Food Waste Behavior among Emerging Adults: Evidence from China. Foods, 9(961); doi:10.3390/foods9070961, 1-19.

van der Werf, P., Seabrook J. A., \& Gilliland, J. A. (2019). Food for naught: Using the theory of planned behaviour to better understand household food wasting behavior. The Canadian Geographer. 63(3):473-493.

Wang. L., Xue L., Xiaojie. L., Shengkui C., \& Gang. L. (2018). Horeca food waste and its ecological footprint in Lhasa, Tibet, China. Resources, Conservation \& Recycling 136 (2018) 1-8.

Watson, M., \& Meah, A. (2012). Food, waste and safety: Negotiating conflicting social anxieties into the practices of domestic provisioning. The Sociological Review (Keele) 60(Suppl.2): 102--120. 